\title{
Determining the Complex Permittivity of Building Dielectric Materials using a Propagation Constant Measurement
}

\author{
Mohammed Bendaoued ${ }^{1}$, Jaouad Terhzaz ${ }^{2}$, Rachid Mandry ${ }^{3}$ \\ ${ }^{1,3}$ Hassan University I FSTS, LMEET, Settat, Morocco \\ ${ }^{2}$ Regional Center for the Trades of Education and Training (CRMEF), Casablanca-settat, Morocco
}

\section{Article Info \\ Article history: \\ Received Jan 9, 2017 \\ Revised Mar 10, 2017 \\ Accepted Mar 25, 2017 \\ Keyword: \\ Dielectric materials \\ Propagation constant \\ Rectangular waveguide \\ X-band}

\author{
Corresponding Author: \\ Mohammed Bendaoued, \\ Departement of Physical Sciences, \\ Université Hassan I FSTS, LMEET. Settat, Morocco. \\ Email: mohammed.bendoued@gmail.com
}

\begin{abstract}
This paper presents a technique to determine the Dielectric constant and dielectric loss of the building dielectric materials using propagation constant measurements. The material sample is loaded in an X-band $(8.5 \mathrm{GHz}$ $12.5 \mathrm{GHz}$ ) rectangular waveguide and its two port S-parameters are measured as a function of frequency using a Vector Network Analyzer without TRL Calibration. The results obtained from samples of dielectric materials (Air, Cellular concrete and Wood) on the X-band frequencies show the validity of the proposed technique to determine the complex permittivity of the building dielectric materials on the X-band frequencies.
\end{abstract}

Copyright () 2017 Institute of Advanced Engineering and Science. All rights reserved.

\section{INTRODUCTION}

The knowledge of dielectric properties is very important for the use as circuit substrate and in the study of electromagnetic energy absorption[1], [2]. Nowadays, several techniques have been developed and used to estimate the dielectric properties of materials. These include free space techniques [3], cavity resonators techniques [4], [5], and transmission line or waveguide methods [4]. Each technique has its distinct advantages and drawbacks. The free space techniques are used when the material is available in a big sheet form and are less accurate [3]. Resonant methods have much better accuracy, but are limited to narrow band frequencies [5]. For measurements of complex permittivity of a material over a wideband of frequencies, transmission line, or waveguide techniques are widely used [6]. The waveguide techniques are accurate for the measurement of complex permittivity. These techniques require a calibrated scattering parameters measurements for estimate the dielectric properties of materials [7-9].

In this work, we propose a technique based on Sij-parameters of rectangular waveguide in T/R to estimate the complex permittivity of the building dielectric materials on the X-band frequencies. The advantage of this technique is to determine dielectric constant and dielectric loss of the building dielectric Literature review that has been done author used in the chapter "Introduction" to explain the difference of the manuscript with other papers, that it is innovative, it are used in the chapter "Research Method" to describe the step of research and used in the chapter "Results and Discussion" to support the analysis of the results [2]. If the manuscript was written really have high originality, which proposed a new method or algorithm, the additional chapter after the "Introduction" chapter and before the "Research Method" chapter can be added to explain briefly the theory and/or the proposed method/algorithm [4]. materials using only the propagation constant measurement of a rectangular waveguide loaded with the material sample to be characterized without Calibration of the Vector Network Analyzer. 
The technique supposes that material is not magnetic and only the fundamental mode TE10 propagates through the structure. The dielectric constant and dielectric loss of the Air, Wood and Cellular Concrete at X-band frequencies are determined by this technique.

\section{PRINCIPLE OF THE PROPAGATION CONSTANT METHOD}

To determine the propagation constant of a rectangular waveguide in Transmission / reflection, we use two rectangular waveguides with same geometry but different lengths d1 and d2. Measuring the Sijparameters (without calibration) of the two rectangular waveguides gives respectively the scattering matrices $\mathrm{S} 1$ and $\mathrm{S} 2$ :

$$
\mathrm{S}_{1 \mathrm{i}}=\left[\begin{array}{ll}
\mathrm{S}_{11 \mathrm{i}} & \mathrm{S}_{12 \mathrm{i}} \\
\mathrm{S}_{21 \mathrm{i}} & \mathrm{S}_{22 \mathrm{i}}
\end{array}\right] \quad \mathrm{i}=1,2
$$

We calculate from these two matrices, T1 and T2 transmissions matrices using the following Equation [10]:

$$
M_{1 \mathrm{i}}=\frac{1}{S_{21 \mathrm{i}}}\left[\begin{array}{cc}
\mathrm{S}_{12 \mathrm{i}} \mathrm{S}_{21 \mathrm{i}}-\mathrm{S}_{11 \mathrm{i}} \mathrm{S}_{22 \mathrm{i}} & \mathrm{S}_{11 \mathrm{i}} \\
-\mathrm{S}_{22 \mathrm{i}} & 1
\end{array}\right]
$$

These two transmissions matrices can also be written as a product of three matrices:

$$
\mathrm{M}_{\mathrm{i}}=\mathrm{X} \mathrm{T}_{\mathrm{i}} \mathrm{Y}
$$

Where $\mathrm{X}$ and $\mathrm{Y}$ are the error matrices representing the imperfections of the Vector Network Analyzer and the effects of cable realizing the interconnections [7]. It is assumed that the two matrices $\mathrm{X}$ and $\mathrm{Y}$ are invariant for each transmission line connected to the network analyzer. Ti is the transmission matrix for an ideal rectangular waveguide of length di and defined by

$$
\mathrm{T}_{\mathrm{i}}=\left[\begin{array}{cc}
\mathrm{e}^{-\gamma \mathrm{d}_{\mathrm{i}}} & 0 \\
0 & \mathrm{e}^{-\gamma \mathrm{d}_{\mathrm{i}}}
\end{array}\right]
$$

Where $\gamma$ is the propagation constant of the rectangular waveguide. The measured two transmission matrices T1 and T2 can be combined as follows:

$$
\begin{aligned}
& \mathrm{M}^{12}=\mathrm{X} \mathrm{T}^{12} \mathrm{X}^{-1} \\
& \text { Or } \quad \mathrm{T}^{12}=\mathrm{T}_{2}\left[\mathrm{~T}_{1}\right]^{-1} \text { and } \mathrm{M}^{12}=\mathrm{M}_{2}\left[\mathrm{M}_{1}\right]^{-1}
\end{aligned}
$$

The relation shows that T12 and M12 are similar matrices. This implies that their eigenvalues are identical. The two eigenvalues $\lambda 1 \mathrm{M}$ and $\lambda 2 \mathrm{M}$ of M12 matrix are given by the following relationship:

$$
\lambda_{1 \mathrm{M}}, \lambda_{2 \mathrm{M}}=\frac{\mathrm{M}_{11}^{12}+\mathrm{M}_{22}^{12} \pm \sqrt{\left(\mathrm{M}_{11}^{12}-\mathrm{M}_{22}^{12}\right)^{2}+4 \mathrm{M}_{12}^{12} \mathrm{M}_{21}^{12}}}{2}
$$

Where are Mij12 with elements of the matrix M12. $\lambda 1 \mathrm{M}$ and $\lambda 2 \mathrm{M}$ are calculated directly from the measurements. The two eigenvalues $\lambda 1 \mathrm{~T}$ and $\lambda 2 \mathrm{~T}$ of $\mathrm{T} 12$ matrix are given by Equation (4): 
$\lambda_{1 \mathrm{~T}}, \lambda_{2 \mathrm{~T}}=\mathrm{e}^{ \pm \gamma\left(\mathrm{d}_{2}-\mathrm{d}_{1}\right)}$

Combining Equation (6) and (7) to solve for the propagation constant $\gamma$ :

$$
\gamma=\frac{\operatorname{Ln}\left(\lambda_{m}\right)}{d_{2}-d_{1}}
$$

where $\lambda \mathrm{m}$ is the average of the two eigenvalues $\lambda 1 \mathrm{~T}$ and $\lambda 2 \mathrm{~T}$ :

$$
\lambda_{\mathrm{m}}=\frac{1}{2}\left(\lambda_{1 \mathrm{~T}}+\frac{1}{\lambda_{2 \mathrm{~T}}}\right)
$$

This method can also be applied to when $\mathrm{d} 1=0$, in this case, measurement of the transmission line of length $\mathrm{d} 1$ corresponds to the measurement "Thru".

If we consider only the fundamental mode TE10 propagates through the structure. The propagation constant of a rectangular waveguide filled with a non-magnetic dielectric material $\left(\mu^{*} \mathrm{r}=1\right)$ to be characterized is given by the following relationship [5]:

$$
\gamma=\mathrm{j}\left(\frac{2 \pi}{\lambda_{\mathrm{o}}}\right) \sqrt{\varepsilon_{\mathrm{r}}^{*}-\left(\frac{\lambda_{\mathrm{o}}}{\lambda_{\mathrm{c}}}\right)^{2}}
$$

Where $\lambda c$ is the cutoff wavelength of the rectangular waveguide. $\lambda 0$ is the length in vacuum at the frequency. From Equation (10) we determine the expression of $\varepsilon^{*} \mathrm{r}$ as a function of the propagation constant:

$$
\varepsilon_{\mathrm{r}}^{*}=\left[1-\left(\frac{\lambda_{\mathrm{O}}}{\lambda_{\mathrm{c}}}\right)^{2}\right]\left(\frac{\gamma}{\gamma_{\mathrm{O}}}\right)^{2}+\left(\frac{\lambda_{\mathrm{O}}}{\lambda_{\mathrm{c}}}\right)^{2}
$$

Where $\gamma 0$ is the propagation constant of the empty rectangular waveguide.

\section{MEASUREMENTS AND RESULTS}

The measurement of S-parameters in Transmission/Reflection on X-band frequencies $(8.5 \mathrm{GHz}$ $12.5 \mathrm{GHz}$ ) is performed by a rectangular waveguide WR90 of section $22.86 \times 10.16 \mathrm{~mm} 2$ and length of $1 \mathrm{~cm}$.

This waveguide section is the sample port of the material to be characterized. The sample holder is placed between two waveguides of lengths $12 \mathrm{~cm}$ in X-band, whose role is to filter the higher order modes. The Vector network analyzer in the range of $50 \mathrm{Mz}-20 \mathrm{GHz}$ frequencies is connected to two Coaxial-guide transitions $(3.5 \mathrm{~cm})$ that ensure the passage of the TEM propagation mode to TE10 mode and vice versa. Measuring device is shown in Figure 1.

The validity of the measurement technique developed in this work is tested initially on the dielectric characterization of the empty cell in X-band. Figure 2 shows the evolution of dielectric constant and dielectric loss of the air on the X-band frequencies. The results obtained correspond to the properties dielectric of the air on the X-band.

After validating the proposed technique, the dielectric constant and the dielectric loss of the Cellular Concrete are determined on the X-band. The Cellular Concrete has a heterogeneous structure consisting of cement powder, sand and air bubble. The sample of the Cellular Concrete is sufficiently machined to the same dimensions of the rectangular waveguide section in X-band $22.86 \times 10.16 \mathrm{~mm}^{2}$ with length equal to 1 $\mathrm{cm}$, in order to minimize the effect of the gap between conductive walls and the sample of the Cellular Concrete. The results are shown in Figure 3, we can conclude that the Cellular Concrete is a low loss dielectric material in the X-band and the average value of measured dielectric constant equal 1.98. The results obtained are in good agreement with the results given in the literature.

To validate the technique without calibrated VNA, another sample of wood was machined to the same dimensions of the rectangular waveguide section in X-band $22.86 \times 10.16 \mathrm{~mm}^{2}$ with length equal to 1 $\mathrm{cm}$. Figure 4 shows the evolution of dielectric constant and dielectric loss of the Wood on the X-band

\footnotetext{
Determining the Complex Permittivity of Building Dielectric Materials using .... (Mohammed Bendaoued)
} 
frequencies. The results obtained for the dielectric constant and dielectric loss of the Wood by using the procedure described in this work are in good agreement with the results obtained of the same sample of Wood using iterative Nicholson Ross method [11].

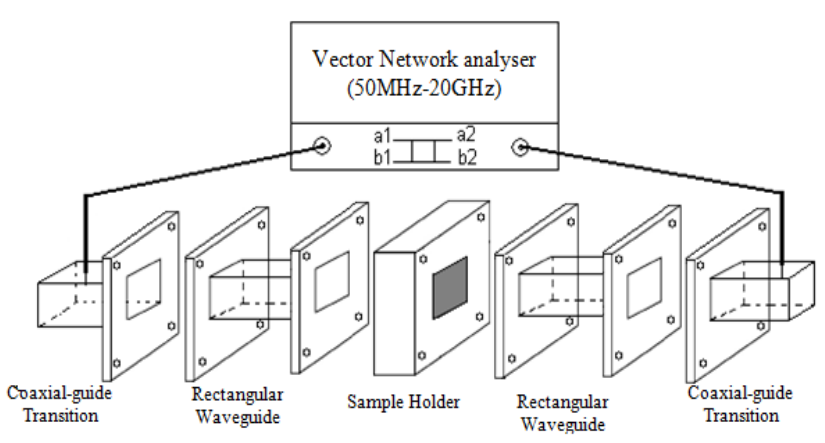

(a)

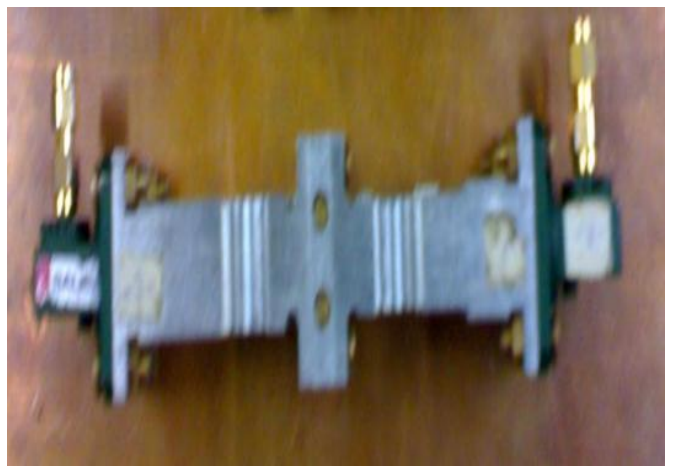

(b)

Figure 1. Measuring device in Transmission/Reflection. (a) Detailed view (b) Photograph
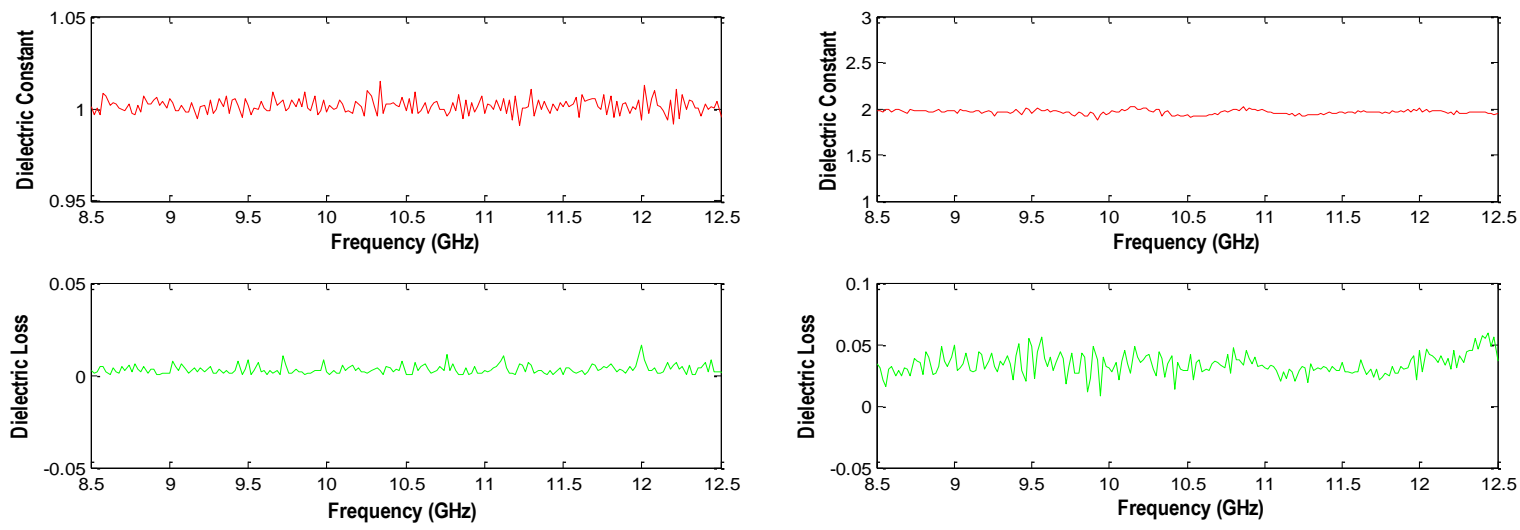

Figure 2. Dielectric constant and dielectric loss of the air on the X-band

Figure 3. Dielectric constant and dielectric loss of the Cellular concrete on the X-band
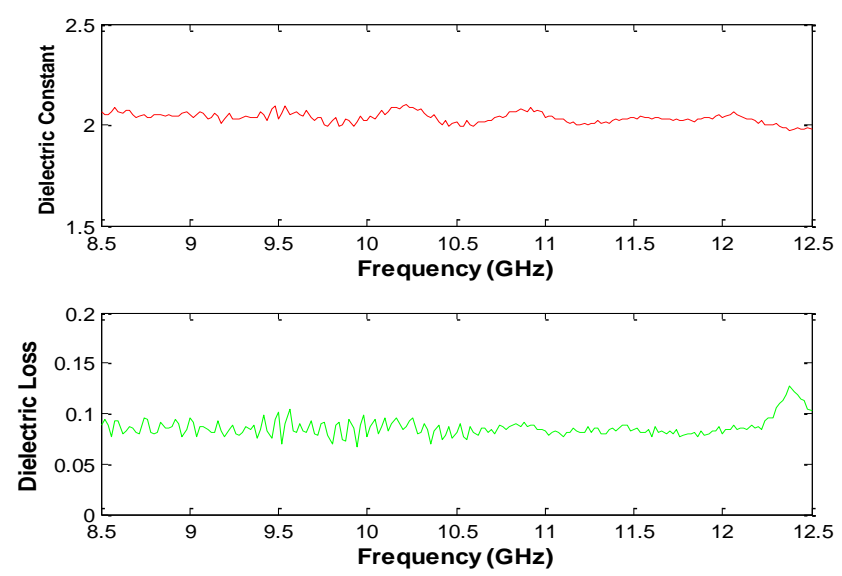

Figure 4. Dielectric constant and dielectric loss of the Wood on the X-band 


\section{CONCLUSION}

In this paper, we have developed a new technique to determine dielectric constant and dielectric loss of building dielectric materials at the X-band frequencies. The method proposed in this work is based on the use of one line to extract the propagation constant from Sij-parameters. The Sij-parameters are measured as a function of frequency using a Vector Network Analyzer without TRL Calibration. The results obtained from samples of dielectric materials (Air, cellular concrete and Wood) on the X-band frequencies allow validation of the proposed technique to determine dielectric constant and dielectric loss of building dielectric materials

\section{REFERENCES}

[1] P.K. Singhal, Bimal Garg, "Design and Characterization of Compact Microstrip Patch Antenna using Split Ring Shaped Metamaterial Structure", IJECE ,Vol.2, No.5, pp. 655-662, October 2012.

[2] Md. Maruf Ahamed, et. al., "Rectangular Microstrip Patch Antenna at 2GHZ on Different Dielectric Constant for Pervasive Wireless Communication", IJECE, Vol.2, No.3, pp. 417- 424, June 2012.

[3] Awang, Z, et. al., "A Free-space Method for Complex Permittivity Measurement of Bulk and thin Film Dielectrics at Microwave Frequencies”, Progress In Electromagnetics Research B.,51, 307-328, 2013.J. Baker-Jarvis,

[4] A. M. Nicholson, G. F. Ross, "Measurement of the Intrinsic Properties of Materials by Time Domain Techniques", IEEE Trans. Instrum. Meas., vol. IM-19, pp. 377-382, November 1970.

[5] F. Sagnard, F. Bentabet, C. Vignat, IEEE Trans. On Instrumentation \& Measurement, vol. 54, no. 3, 1274, June 2005.

[6] J. Baker-Jarvis, "Transmission/Reflection and Short-Circuit Line Permittivity Measurements", National Institute of Standards and Technology, Boulder, Colorado 80303-3328, July 1990.

[7] G. F. Engen, C. A. Hoer, "Thru-Reflect-Line: An Improved Technique for Calibrating the Dual Six-port Automatic Network Analyser", IEEE Trans. On MTT, vol. 45, no. 12, pp.987-993, December 1979.

[8] Hasar, U. C., "A New Calibration-independent Method for Complex Permittivity Extraction of Solid Dielectric Materials," IEEE Microwave Wireless Compon. Letters, vol. 18, no. 12, pp. 788-790, 2008.

[9] U. C. Hasar, O. Simsek, "On the Application of Microwave Calibration-independent Measurements for Noninvasive Thickness Evaluation of Medium or low Loss Solid Materials", Progress In Electromagnetics Research, PIER91, pp. 377-392, 2009.

[10] M. D. Janezic, J. A. Jargon, "Complex Permittivity Determination from Propagation Constant Measurements", IEEE Microwave and Guided Wave Letters, vol.9, no. 2, February 1999.

[11] Baker-Jarvis J, Vanzur E J, Kissick, W A, "Improved Technique for Determining Complex Permittivity with the Transmission/Reflection Method", IEEE Transactions Microwave Theory and Techniques, vol. 38, no. 8, pp. 1096-1103, 1990

\section{BIOGRAPHIES OF AUTHORS}

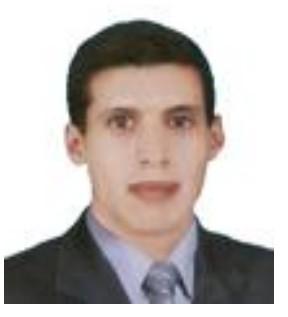

Mohammed Bendaoued received a diploma in Phsyque-electronic theory, A faculty of sciences of fes in 2009 and Diploma of Master sepicilite Micro-elctronics. At the Faculty of Science, Kenitra, 2012. Currently, he is pursuing Ph.D. at the University FST settat Morocco.In the field of electronic telecomminication. Its current field of research is the use, determination of the dielectric permittivity of solid materials For monitoring concret

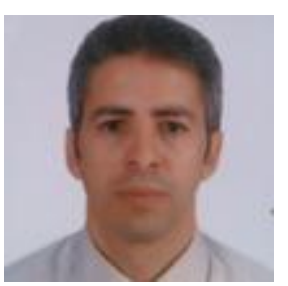

Jaouad Terhzaz was born in Morocco, in September 1977. He received the PH.D degree in electronics and telecommunications from the Mohammadia School of engineering (EMI), Mohammed V University-Agdal, Rabat, Morocco, in 2008. He is currently a professor in department of physical sciences in CRMEF, Casablanca-Settat, Morocco. He is involved in dielectric characterization of materials using microwave techniques and antennas systems design for mobile communications

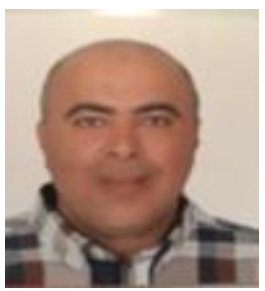

Rachid Mandry was born in Morocco, in December 1967. He received the PH.D degree in physics from the Claude Bernard University- Lyon, France in 1993. He is currently an associate professor in department of physical sciences, FST in University of Hassan 1st, Settat, Morocco. He is involved in microwave components and antennas design for wireless communications. 